\title{
A hydraulic instability drives the cell death decision in the nematode germline
}

\author{
Nicolas T. Chartier ${ }^{1,9}$, Arghyadip Mukherjee $\mathbb{C}^{2,3,4,9}$, Julia Pfanzelter ${ }^{1,2,9}$, Sebastian Fürthauer ${ }^{5}{ }^{5}$,

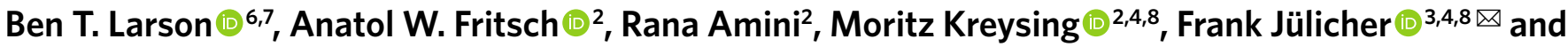 \\ Stephan W. Grill $\mathbb{1 B}^{1,2,4,8 \bowtie}$
}

\begin{abstract}
Oocytes are large cells that develop into an embryo upon fertilization'. As interconnected germ cells mature into oocytes, some of them grow-typically at the expense of others that undergo cell death ${ }^{2-4}$. We present evidence that in the nematode Caenorhabditis elegans, this cell-fate decision is mechanical and related to tissue hydraulics. An analysis of germ cell volumes and material fluxes identifies a hydraulic instability that amplifies volume differences and causes some germ cells to grow and others to shrink, a phenomenon that is related to the two-balloon instability ${ }^{5}$. Shrinking germ cells are extruded and they die, as we demonstrate by artificially reducing germ cell volumes via thermoviscous pumping ${ }^{6}$. Our work reveals a hydraulic symmetry-breaking transition central to the decision between life and death in the nematode germline.

The germline of the adult Caenorhabditis elegans hermaphrodite captures all the essential features to identify the mechanisms by which germ cells are selected to live or die. The nematode gonad is a tubular syncytium consisting of germ cells that surround a central cytoplasmic compartment called rachis, to which all the germ cells are connected via openings called rachis bridges ${ }^{3,7-10}$ (Fig. 1a). Germ cells originate in a mitotic zone from a pool of stem cells residing in the distal tip of each gonad arm, and undergo meiotic maturation as they move towards the proximal turn ${ }^{3,11}$. During this progression, some of the germ cells grow to become oocytes, while the rest shrink and die by physiological apoptosis ${ }^{12}$ (Fig. 1a). Although the core apoptotic machinery was shown to drive the final steps of cell death, the mechanisms that select and initiate apoptosis in individual germ cells are still unclear ${ }^{13,14}$.
\end{abstract}

Oocyte growth in C. elegans has been shown to rely on long-range cytoplasmic streaming ${ }^{15,16}$, but how and why germ cells shrink remains elusive. To identify a potential relationship between germ cell growth, shrinkage and apoptosis, we first set out to both quantify where germ cells grow along the gonad and characterize how this growth proceeds (Fig. 1b). Confocal imaging followed by three-dimensional (3D)-membrane-based segmentation of adult germlines expressing the membrane marker mCherry:: $\mathrm{PH}(\mathrm{PLC} 1 \mathrm{delta} 1)$ allowed us to measure individual germ cell volumes along the distal to proximal axis until the turn region (Supplementary Video 1). We find that germ cells near the distal tip have a volume of approximately $100 \mathrm{fl}$. As germ cells mature along the gonad, they first collectively grow in volume to approximately $150 \mathrm{fl}$ (Supplementary Fig. 1a). Before the proximal turn, the variation in germ cell volumes increases drastically, and germ cells range from very small $(\sim 65 \mathrm{fl})$ to very large $(\sim 1,200 \mathrm{fl})$ sizes. While the distribution of germ cell volumes is unimodal in the distal region, it becomes bimodal close to the turn (Fig. 1b and Supplementary Fig. 1b). This suggests a transition from a homogeneous to a heterogeneous growth mode of germ cells along the gonad. To identify the precise location where this transition occurs, we investigated the average and standard deviation of germ cell volumes in different regions along the gonad (Fig. 1b, bottom inset). Both quantities appear to be linearly related but the associated slope changes sharply, which can be used to locate the transition zone to $65 \% \pm 3.75 \%$ germline length. Two alternative methods for investigating the unimodality of distributions to identify the transition zone gave a similar result (Supplementary Information). Note that physiological apoptosis occurs proximal to this transition point, from about $70 \%$ to $90 \%$ germline length (Supplementary Fig. 1c).

Both homogeneous and heterogeneous modes of germ cell growth must rely on the addition of cytosolic volume. Germ cells can either grow by receiving material from the rachis inside or from the surrounding tissue outside, such as the intestine ${ }^{17}$. We set out to identify the two regions of growth from where the corresponding cytosolic volume is available. For this, we made use of the fact that cytosol is incompressible ${ }^{18}$ and determined the volume flux of cytoplasmic material through the rachis along the gonad $Q_{\mathrm{r}}(x)$, where $x$ denotes the position along the distal-proximal axis of the germline (Supplementary Information). In this one-dimensional (1D) representation, the flux balance at the steady state can be expressed as

$$
\partial_{x} Q_{\mathrm{r}}=J
$$

where $J(x)$ denotes the germ-cell-to-rachis current. Hence, an increase in rachis flux $Q_{\mathrm{r}}$ along the gonad implies that germ cells contribute material to the rachis, while a decrease means that germ cells receive material from the rachis. We performed particle image velocimetry (PIV) ${ }^{19}$ on mid-plane confocal sections of the germline expressing LifeAct::mKate to determine a cytoplasmic velocity field inside the rachis, which we then used to infer the steady-state rachis flux (Fig. 1c, Supplementary Video 4 and Supplementary Information). We find that $Q_{r}$ increases monotonically along the distal part of the gonad, peaks at approximately $60 \%$ germline length and decreases thereafter. Hence, $J$ is positive

'Biotechnology Center, TU Dresden, Dresden, Germany. ${ }^{2}$ Max Planck Institute of Molecular Cell Biology and Genetics (MPI-CBG), Dresden, Germany. ${ }^{3}$ Max Planck Institute for the Physics of Complex Systems (MPI-PKS), Dresden, Germany. ${ }^{4}$ Center for Systems Biology Dresden, Dresden, Germany. ${ }^{5}$ Center for Computational Biology, Flatiron Institute, New York, NY, USA. ${ }^{6}$ Department of Molecular and Cell Biology, University of California, Berkeley, CA, USA. ${ }^{7}$ Biophysics Graduate Group, University of California, Berkeley, CA, USA. ${ }^{8}$ Cluster of Excellence-Physics of Life, TU Dresden, Dresden, Germany. ${ }^{9}$ These authors contributed equally: Nicolas T. Chartier, Arghyadip Mukherjee, Julia Pfanzelter. ${ }_{e}$-mail: julicher@pks.mpg.de; grill@mpi-cbg.de 
a
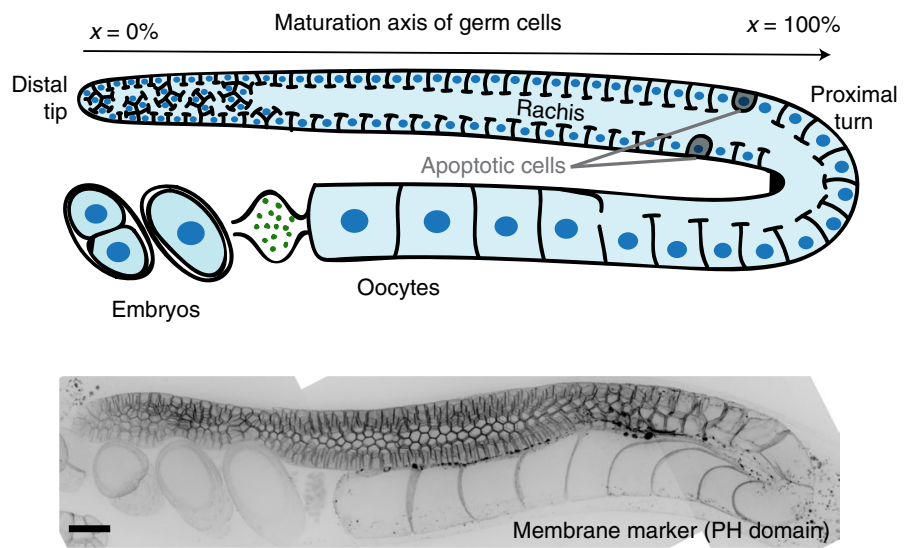

c

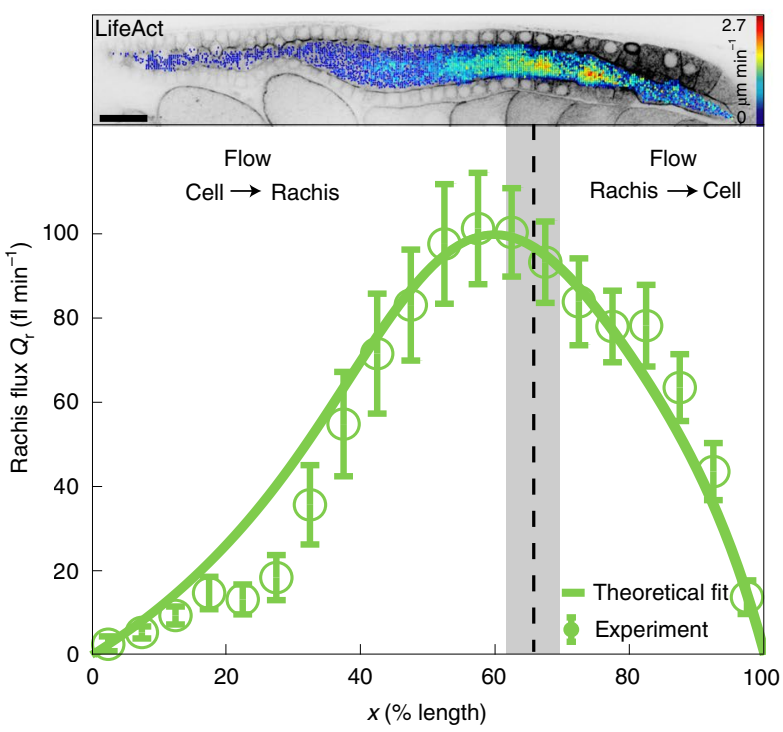

b

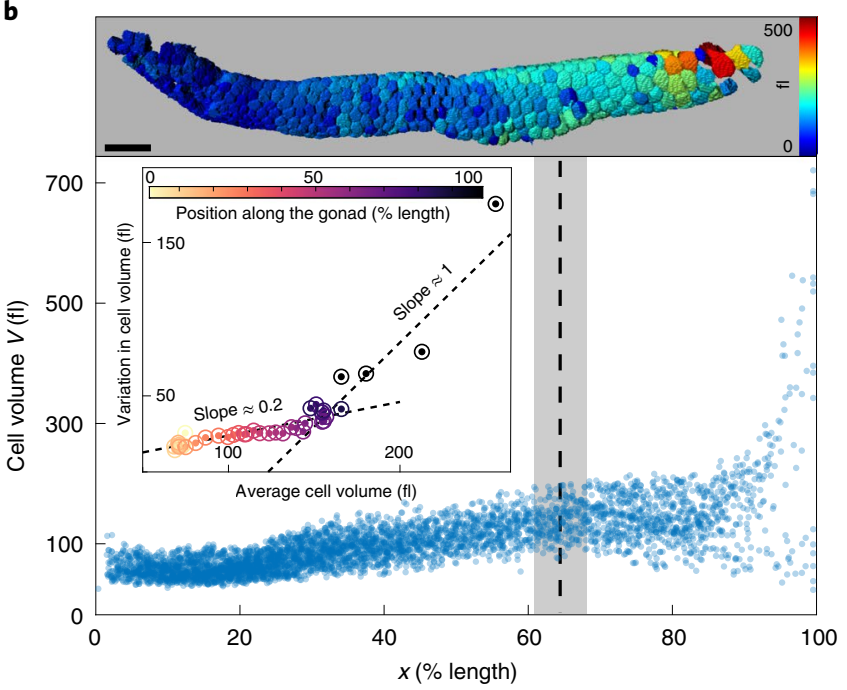

d

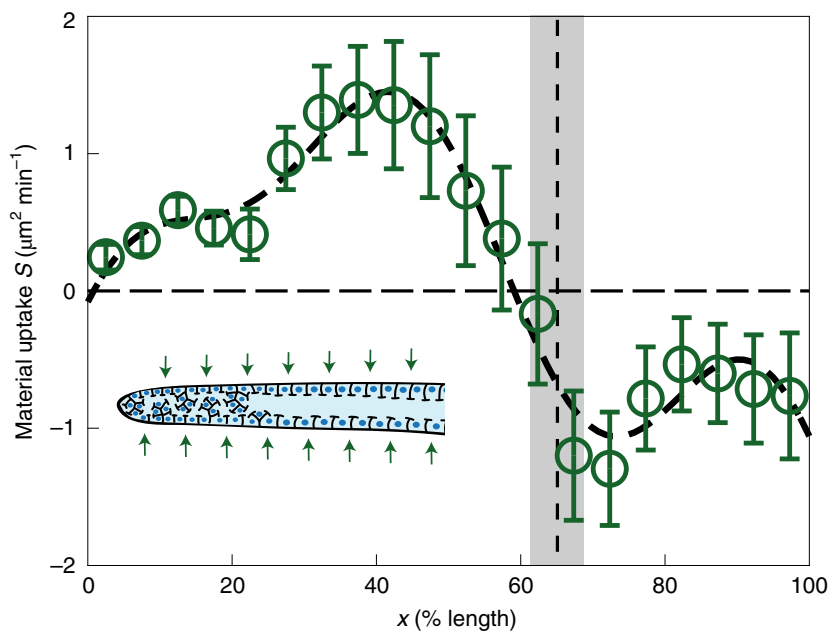

Fig. 1 | Volumes and fluxes in the $\mathbf{C}$. elegans gonad. a, Top: schematic of an adult hermaphrodite gonad arm. Bottom: representative fluorescence image of

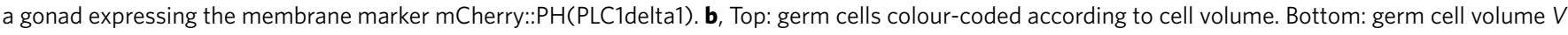
along the gonad from distal tip (0\% length) to proximal turn (100\% length), for 5,265 germ cells from 18 gonad arms (bottom). Inset: s.d. plotted against the average of germ cell volumes determined at 40 colour-coded positions along the gonad. We observe two different relationships between s.d. and average, indicative of a transition between two growth modes. c, Top: cross-section of a gonad expressing LifeAct::mKate overlaid with colour-coded flow speeds as obtained by PIV (Supplementary Information). Bottom: cytoplasmic flux $Q_{r}$ through the rachis as a function of position along the gonad. Open circles, $Q_{r}$ determined from PIV speed distributions obtained from 10 gonad arms. Solid line, best parameter theory fit given the profile of material uptake $S$ shown in d. d, Open circles denote material uptake $S$ into the gonad from the outside, determined by volume conservation of rachis flux (c) and volume flux associated with germ cells moving from distal to proximal (Supplementary Fig. 1e). The thick dashed line shows a smoothened representation of the material uptake profile (Supplementary Information). Inset: green arrows indicate material uptake from the surrounding. The dashed vertical lines and grey boxes in $\mathbf{b}$-d denote the position and associated confidence interval, respectively, where the distribution of germ cell volumes is no longer unimodal. Scale bars, $20 \mu \mathrm{m}$. Error bars indicate the error of the mean at $95 \%$ confidence.

before $60 \%$ germline length and germ cells donate material to the rachis, while $J$ is negative and germ cells receive material from the rachis thereafter.

Interestingly, germ cells grow before $60 \%$ germline length (Figs. $1 \mathrm{~b}$ and Supplementary Fig. 1a) despite losing cytoplasm to the rachis. This implies that they must be receiving material from the outside. We inferred the profile of material uptake $S(x)$ (Fig. 1d) from the total flux balance at the steady state:

$$
\partial_{x}\left(Q_{\mathrm{c}}+Q_{\mathrm{r}}\right)=S
$$

where $Q_{c}(x)$ denotes the volume flux associated with germ cells moving from distal to proximal ${ }^{11}$ (Supplementary Information). We find that in the distal region and up to approximately $60 \%$ gonad length, material uptake $S$ is positive and germ cells grow by receiving material from the outside. Material uptake becomes negative beyond $60 \%$, indicating a loss of material to the outside, possibly via removal of apoptotic cells. We conclude that material associated with the homogeneous growth of germ cells comes from the outside, while the heterogeneous growth mode is associated with germ cells receiving cytoplasm from the rachis. 
a

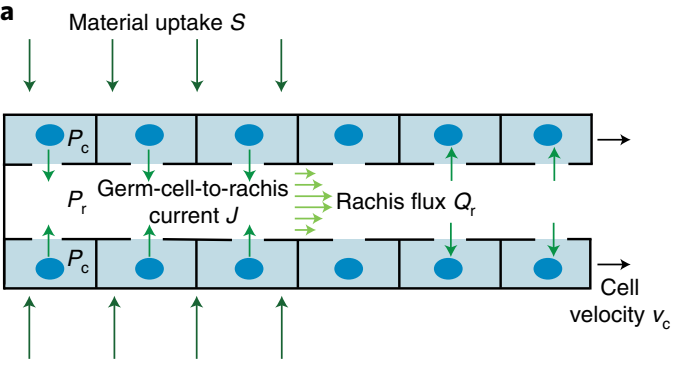

c

Two balloons

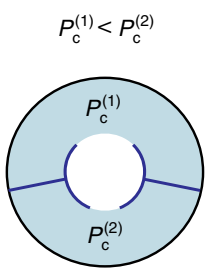

e

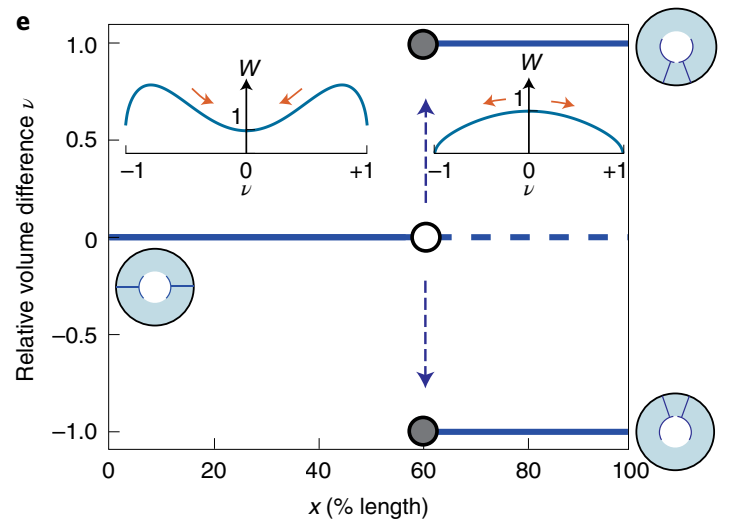

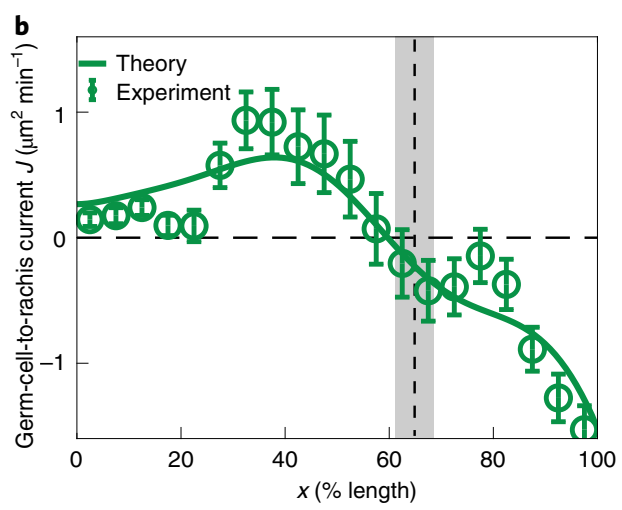

d

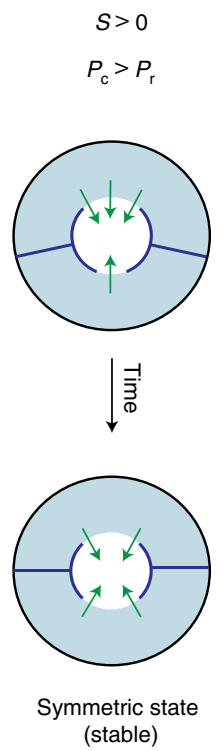

$\simeq 0$

$P_{\mathrm{c}}<P_{\mathrm{r}}$
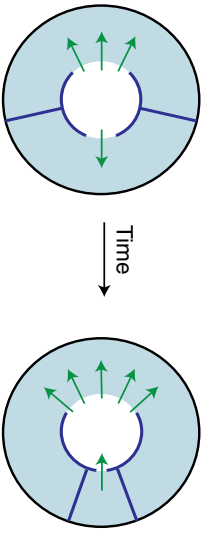

Symmetric state (unstable)

Fig. 2 | A theoretical model of germ cell and rachis fluxes reveals a hydraulic instability. a, Schematic of a 1D hydrodynamic model for pressures, material fluxes and volume exchange in the $C$. elegans gonad. $P_{\mathrm{c}}$ and $P_{\mathrm{r}}$ denote the pressure field in germ cells and rachis, respectively; $S$, profile of material uptake from the outside; J, germ-cell-to-rachis current associated with flows through the rachis bridges; $Q_{r}$, rachis flux; and $v_{c}$, germ cell velocities. $\mathbf{b}$, Green open circles, estimated germ-cell-to-rachis current $J$ along the gonad length; vertical dashed line and grey bar denote the region of transition between the growth modes of germ cells (Fig. 1b). Solid line, best parameter theory fit given the profile of material uptake S shown in Fig. 1d. c, Schematic of a germ cell doublet and two connected balloons depicting how a difference in volumes leads to difference in pressures. $\mathbf{d}$, Evolution of small volume differences between coupled germ cells with time. The symmetric state $(\nu=0)$ of equal germ cell volumes is unstable when the pressure in the rachis is higher than in germ cells (right). Here the initially larger cell grows at the expense of the smaller one. e, Relative volume difference $\nu$ in a cell doublet bifurcates around $60 \%$ germline length where material uptake $S$ vanishes and pressure difference $P_{\mathrm{c}}-P_{\mathrm{r}}$ changes sign. Insets illustrate cell configurations and corresponding effective potentials $W$ as a function of $\nu$ normalized by its value at $\nu=0$ (Supplementary Information). Error bars indicate the error of the mean at $95 \%$ confidence.

The observed inversion of current $J$ around $60 \%$ germline length implies an inversion of the pressure difference across the rachis bridges separating the germ cells from the rachis. To shed light on the underlying force balances, we construct a $1 \mathrm{D}$ physical model that relates pressure profiles to flows of germ cells and rachis cytoplasm as well as material exchange between germ cells and rachis (Fig. $2 \mathrm{a}$ and Supplementary Information). The germ-cell-to-rachis current is driven by differences in germ cell pressure $P_{c}(x)$ and rachis pressure $P_{\mathrm{r}}(x)$, and it can be expressed as $J=\alpha\left(P_{\mathrm{c}}-P_{\mathrm{r}}\right)$. Here $\alpha$ denotes an effective hydraulic conductivity of rachis bridges, which depends on rachis bridge radii. Using the profile of material uptake (Fig. 1d), this theory recapitulates rachis and germ cell fluxes (indicated by solid lines in Fig. 1c and Supplementary Fig. 1e) and predicts a profile of germ-cell-to-rachis current $J$ that matches the experimental estimates (Fig. 2b). Consistent with the observation that the rachis flux peaks around $60 \%$ gonad length, this current changes sign at the same location (Fig. 2b). Because pressure differences drive the germ-cell-to-rachis current $J$, the pressure difference between the cells and rachis, $P_{c}-P_{r}$, also changes sign at this location. Next, we investigated if this inversion of the pressure difference might be the key to understanding the transition from homogeneous to heterogeneous mode of germ cell growth. We note that the change in unimodal to bimodal volume distribution is indicative of instability in the germ cell volumes during growth. Similar instability arises when simultaneously blowing into two rubber balloons in an attempt to inflate them both. Here only one balloon inflates. Because the larger balloon can be inflated at lower pressures than the smaller one, the situation where both simultaneously inflate is mechanically unstable ${ }^{20}$.

Could such an instability also arise in the germline $e^{21-27}$ ? We consider the mechanics of a simplified configuration of two germ cells with volumes $V_{1}$ and $V_{2}$ that surround a common rachis to which they are connected by rachis bridges (Fig. 2c). We take into 

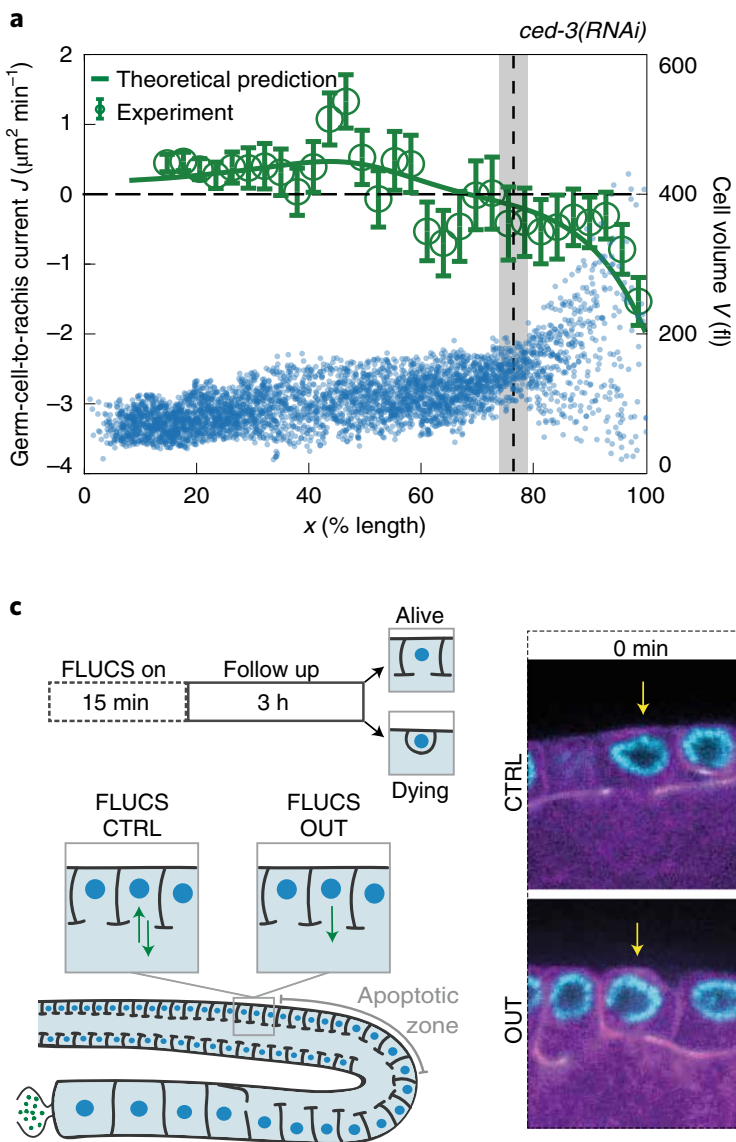

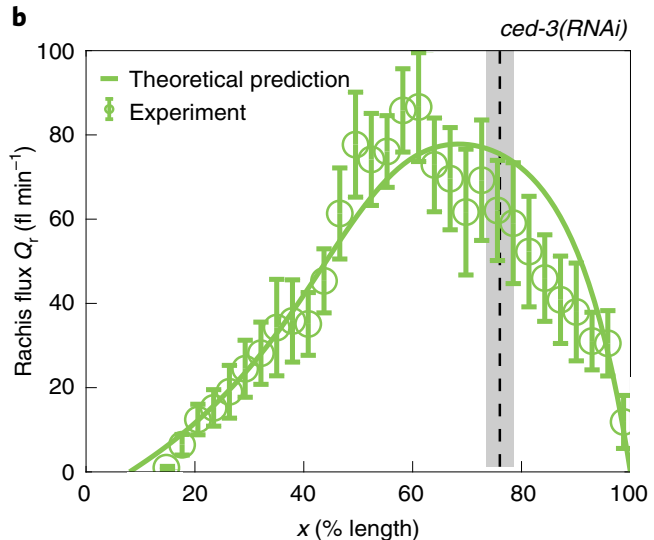

d
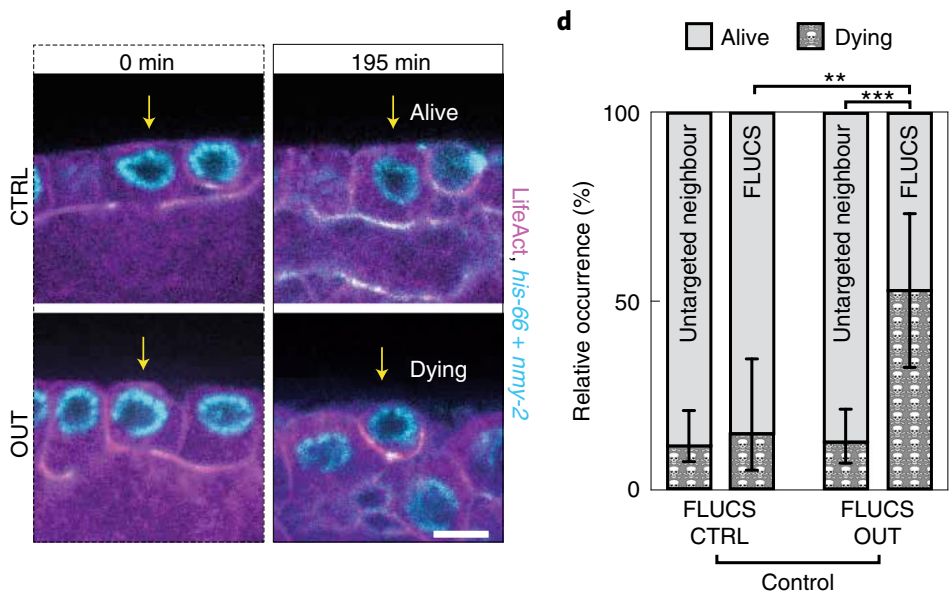

Fig. 3 | A hydraulic instability drives cell shrinkage that triggers cell death. a, Blue dots, cell volume $V$ along the germline for 4,030 germ cells from 7 gonad arms where apoptosis was inhibited by ced-3(RNAi). Vertical dashed lines and grey bars in $\mathbf{a}$ and $\mathbf{b}$ denote the region of transition between the growth modes of germ cells for ced-3(RNAi) (Fig. 1b). Green open circles, germ-cell-to-rachis current $J$ in ced-3(RNAi) along the germline (Supplementary Information). Green line, profile of the germ-cell-to-rachis current $J$ for ced-3(RNAi) as predicted by theory, using physical parameters and the profile of material uptake $S$ obtained for the non-treated control (Supplementary Information, Fig. 1d and Supplementary Fig. 2d). b, Rachis flux $Q_{r}$ along the gonad for ced-3(RNAi) obtained from 9 gonad arms (green open circles; Supplementary Information), together with the corresponding theoretical prediction (green line). c, FLUCS experiments. Left: schematic. Right: representative fluorescence images before and after bidirectional FLUCS as a control (CTRL; top) and unidirectional FLUCS (OUT; bottom) (magenta, LifeAct::mKate; cyan, GFP-nmy-2 and Histone-Dendra). d, Relative occurrence of rachis bridge closure and rounding up within $3 \mathrm{~h}$ for cells treated with FLUCS CTRL or FLUCS OUT and their untargeted neighbours; ${ }^{\star \star} P<0.01$, $\star \star \star P<0.001$. Only the FLUCS OUT-treated cells (right-most bar) displayed a significant increase in commencing apoptosis within $3 \mathrm{~h}$. Scale bar, $5 \mu \mathrm{m}$. Error bars indicate the error of the mean at $95 \%$ confidence.

account force balances due to cortical tension and the fact that material uptake from the outside of each cell is proportional to the basal surface area exposed to the outside. Note that one germ cell can increase in size at the expense of the other. Furthermore, large germ cells tend to have larger rachis bridges than small germ cells (Supplementary Fig. 1f). With these components, we obtain an equation of motion for the relative volume difference $\nu=\left(V_{2}-V_{1}\right) /$ $\left(V_{1}+V_{2}\right)$ (Supplementary Information):

$$
\begin{aligned}
\frac{\mathrm{d} \nu}{\mathrm{d} t}= & -\frac{S}{A_{\mathrm{c}}}(\lambda(\nu)+\nu)-\alpha_{0} \frac{P_{\mathrm{c}}-P_{\mathrm{r}}}{2 A_{\mathrm{c}}} \nu(1-\nu)(1+\nu) \\
& +\alpha_{0} \frac{\Delta P(\nu)}{8 A_{\mathrm{c}}}\left(1+6 \nu^{2}+\nu^{4}\right),
\end{aligned}
$$

where $A_{c}$ is the combined cross-sectional area of the two germ cells; $\lambda$ is the relative difference in the basal surface area of the germ cells, which depends on $\nu$; and $\alpha_{0}$ is the hydraulic conductivity. The average pressure between the two germ cells $P_{\mathrm{c}}^{(1)}$ and $P_{\mathrm{c}}^{(2)}$ can be expressed as $P_{\mathrm{c}}=\left(P_{\mathrm{c}}^{(1)}+P_{\mathrm{c}}^{(2)}\right) / 2$. Pressure in the two germ cells can differ by $\Delta P=P_{\mathrm{c}}^{(1)}-P_{\mathrm{c}}^{(2)}$. This pressure difference $\Delta P$ depends on the relative volume difference $\nu$ and is similar to the pressure difference between two balloons of different sizes (Fig. 2c). For two germ cells, $\Delta P \approx T \nu / R$, where $T$ is an effective cortical tension ${ }^{9,15}$ and $R$ is the radius of the gonad (Supplementary Information). This pressure difference, therefore, tends to destabilize the symmetric configuration with equal germ cell volumes. Two additional contributions in equation (3) can stabilize the symmetric state. First, the effects of material uptake $S>0$ are generally stabilizing. Second, the contributions from the difference in germ cell and rachis pressure become stabilizing when $P_{\mathrm{c}}>P_{\mathrm{r}}$. Hence, material uptake in the distal region $(S>0)$ leads to a situation with $P_{\mathrm{c}}>P_{\mathrm{r}}$, both of which stabilize the symmetric state of equal germ cell volume in this region. At around $60 \%$ gonad length, material uptake vanishes $(S \approx 0)$ leading to inversion of the pressure difference $P_{\mathrm{c}}-P_{\mathrm{r}}$ at a point slightly proximal to the point at which the uptake vanishes (Figs. 1d and $2 \mathrm{~b}$ ). Beyond this point, the stabilizing effects are absent and the symmetric state is, therefore, unstable. As a result, small differences in germ cell volumes increase, leading to the growth of the larger germ cell at the expense of the smaller one until the small cell loses its cytoplasm 
at $\nu= \pm 1$ (Fig. 2d). Equation (3) can be expressed in terms of an effective potential $\mathrm{d} \nu / \mathrm{d} t=-\mathrm{d} W / \mathrm{d} \nu$ (Fig. 2e, inset). This effective potential $W$ either has a single minimum at $\nu=0$ when the symmetric state with $\nu=0$ is stable or exhibits two minima at $\nu= \pm 1$ corresponding to the two completely asymmetric configurations, while the symmetric state at $\nu=0$ is at a maximum. Hence, germ cells undergo homogeneous growth in the distal region before $60 \%$, beyond which they undergo heterogeneous growth as is observed in this regime (beyond 65\% gonad length; Fig. 1b). The transition between these two regimes is associated with a hydraulic instability, which is triggered by the loss of material uptake and the associated inversion of the pressure difference $P_{\mathrm{c}}-P_{\mathrm{r}}$.

This hydraulic instability presents a possible mechanism by which germ cells become fated to die: generating a few large cells at the expense of smaller shrinking cells in a coarsening process. Apoptosis is then triggered in shrinking cells, which leads to their removal. However, an alternative scenario is that unknown molecular signals first induce apoptosis, which subsequently leads to the shrinkage of those cells fated to die. To test this alternative possibility, we inhibited the apoptosis of germ cells by RNA interference $(\mathrm{RNAi})^{28}$ targeted against the caspase CED-3 (refs. ${ }^{12,13}$ ) and evaluated if germ cells still shrink. We find that in the absence of apoptosis, germ cells are no longer removed ${ }^{12}$; however, we still observe that some cells in the proximal region shrink (blue dots in Fig. 3a). Similar to unperturbed conditions, ced-3(RNAi) gonads show a transition from a homogeneous to a heterogeneous mode of growth (grey bar in Fig. 3a); further, the position of this transition is close but a bit proximal to the location where both germ-cell-to-rachis current and pressure difference between the germ cells and rachis change sign (Fig. 3a), and where the rachis flux peaks (Fig. 3b). Together, this eliminates apoptosis as the cause of germ cell shrinkage and supports the idea that germ cell fate is determined by a hydraulic instability.

Our results suggest that a hydraulic instability generates large and small germ cells; the latter are eliminated by physiological apoptosis. This implies that increasing the number of small germ cells should lead to an increase in apoptotic germ cells. To test this, we depleted the small anillin isoform ANI-2 by RNAi, which is reported to affect the germline architecture and result in smaller germ cells ${ }^{29}$. Indeed, treatment with ani-2(RNAi) led to a higher fraction of proximal germ cells smaller than $\sim 150 \mathrm{fl}$ (Supplementary Fig. 2f,g) and a concomitant increase in the number of apoptotic cells $^{29,30}$ (Supplementary Fig. 2h). Next, we set out to test if we can bias the outcome of this hydraulic decision-making process via direct mechanical manipulation. In particular, artificially reducing the volume of individual germ cells should increase their likelihood to undergo apoptosis. We tested this prediction by unidirectional thermoviscous pumping (focused-light-induced cytoplasmic streaming (FLUCS) $)^{6}$ for 15-20 min to pump germ cell cytoplasm out of individual germ cells through their rachis bridge, and monitoring the subsequent fate of the manipulated cells for $3 \mathrm{~h}$ (Fig. $3 \mathrm{c}$ ). As a control, we performed bidirectional FLUCS by rapidly switching between pumping cytoplasm into and out of individual germ cells, with an overall similar dosage of laser light but without inducing a net flow (Supplementary Video 5). In the control scenario, $14.3 \%$ germ cells ( 3 out of 21 ) commence apoptosis within the following $3 \mathrm{~h}$ (Fig. $3 \mathrm{~d}$ ), as judged by a characteristic rounding up of apoptotic germ cells ${ }^{12}$. This number favourably compares with the rates of apoptosis in the unperturbed situation, since an apoptotic rate of $4-6 \%$ per hour (Supplementary Fig. 1c) leads to $11.5-17 \%$ germ cells commencing apoptosis within $3 \mathrm{~h}$ (Methods; note that we arrive at similar numbers when analysing neighbouring cells not subjected to FLUCS (Fig. 3d)). In contrast, 52.6\% germ cells (10 out of 19) commence apoptosis within the three hours following unidirectional FLUCS (Fig. 3c,d and Supplementary Video 6). We conclude that a hydraulic manipulation to reduce the volume of individual germ cells results in an increased likelihood of commencing apoptosis. Together, this lends credence to the statement that the life and death decision in the gonad is of mechanical nature.

The hydraulic instability that we have discovered amplifies small differences in germ cell volumes and redistributes material from smaller to larger cells. This is consistent with observations in which larger oocytes continued to grow at the expense of smaller neighbours even after the blockage of rachis with an oil drop ${ }^{15}$. Because germ cell fate is determined by size, the mechanism selects for larger-and perhaps-fitter cells while making use of the resources of the dying ones ${ }^{29,31}$. The mechanism we have discovered here bases a cell-fate decision on a hydraulic instability, presenting a robust alternative to biochemical switches usually invoked in cellular decision-making processes $^{32-34}$.

\section{Online content}

Any methods, additional references, Nature Research reporting summaries, source data, extended data, supplementary information, acknowledgements, peer review information; details of author contributions and competing interests; and statements of data and code availability are available at https://doi.org/10.1038/ s41567-021-01235-x.

Received: 15 September 2020; Accepted: 30 March 2021; Published online: 20 May 2021

\section{References}

1. Gerhart, J. \& Kirschner, M. Cells, Embryos and Evolution (Wiley, 1997).

2. Pepling, M. E. From primordial germ cell to primordial follicle: mammalian female germ cell development. Genesis 44, 622-632 (2006).

3. Kimble, J. \& Ward, S. Germline Survival and Apoptosis (Cold Spring Harbor Press, 1988).

4. Lei, L. \& Spradling, A. C. Mouse oocytes differentiate through organelle enrichment from sister cyst germ cells. Science 352, 95-99 (2016).

5. Weinhaus, F. \& Barker, W. On the equilibrium states of interconnected bubbles or balloons. Am. J. Phys. 46, 978-982 (1978).

6. Mittasch, M. et al. Non-invasive perturbations of intracellular flow reveal physical principles of cell organization. Nat. Cell Biol. 20, 344-351 (2018)

7. Amini, R. et al. C. elegans Anillin proteins regulate intercellular bridge stability and germline syncytial organization. J. Cell Biol. 206, 129-143 (2014).

8. Lee, K.-Y. et al. CYK-4 functions independently of its centralspindlin partner ZEN-4 to cellularize oocytes in germline syncytia. eLife 7, e36919 (2018).

9. Priti, A. et al. Syncytial germline architecture is actively maintained by contraction of an internal actomyosin corset. Nat. Commun. 9, 4694 (2018).

10. Rehain-Bell, K. et al. A sterile 20 family kinase and its co-factor CCM-3 regulate contractile ring proteins on germline intercellular bridges. Curr. Biol. 27, 860-867 (2017).

11. Mattingly, H. H., Chen, J. J., Arur, S. \& Shvartsman, S. Y. A transport model for estimating the time course of ERK activation in the C. elegans germline. Biophys. J. 109, 2436-2445 (2015).

12. Gumienny, T. L., Lambie, E., Hartwieg, E., Horvitz, H. R. \& Hengartner, M. O. Genetic control of programmed cell death in the Caenorhabditis elegans hermaphrodite germline. Development 126, 1011-1022 (1999).

13. Gartner, A., Boag, P. R. \& Blackwell, T. K. Germline survival and apoptosis In WormBook: The Online Review of C. elegans Biology (WormBook, 2018).

14. Raiders, S. A., Eastwood, M. D., Bacher, M. \& Priess, J. R. Binucleate germ cells in Caenorhabditis elegans are removed by physiological apoptosis. PLoS Genet. 14, e1007417 (2018).

15. Wolke, U., Jezuit, E. A. \& Priess, J. R. Actin-dependent cytoplasmic streaming in C. elegans oogenesis. Development 134, 2227-2236 (2007).

16. Nadarajan, S., Govindan, J. A., McGovern, M., Hubbard, E. J. A. \& Greenstein, D. MSP and GLP-1/Notch signaling coordinately regulate actomyosin-dependent cytoplasmic streaming and oocyte growth in $C$. elegans. Development 136, 2223-2234 (2009).

17. Grant, B. \& Hirsh, D. Receptor-mediated endocytosis in the Caenorhabditis elegans oocyte. Mol. Biol. Cell 10, 4311-4326 (1999).

18. Niwayama, R., Shinohara, K. \& Kimura, A. Hydrodynamic property of the cytoplasm is sufficient to mediate cytoplasmic streaming in the Caenorhabiditis elegans embryo. Proc. Natl Acad. Sci. USA 108, 11900-11905 (2011).

19. Thielicke, W. \& Stamhuis, E. PIVlab-towards user-friendly, affordable and accurate digital particle image velocimetry in MATLAB. J. Open Res. Softw. 2, p.e30 (2014)

20. Dreyer, W., Müller, I. \& Strehlow, P. A study of equilibria of interconnected balloons. Q. J. Mech. Appl. Math. 35, 419-440 (1982). 
21. Charras, G. T., Yarrow, J. C., Horton, M. A., Mahadevan, L. \& Mitchison, T. Non-equilibration of hydrostatic pressure in blebbing cells. Nature 435, 365-369 (2005).

22. Sedzinski, J. et al. Polar actomyosin contractility destabilizes the position of the cytokinetic furrow. Nature 476, 462-466 (2011).

23. Casares, L. et al. Hydraulic fracture during epithelial stretching. Nat. Mater. 14, 343-351 (2015).

24. Dumortier, J. G. et al. Hydraulic fracturing and active coarsening position the lumen of the mouse blastocyst. Science 365, 465-468 (2019).

25. Chan, C. J. et al. Hydraulic control of mammalian embryo size and cell fate. Nature 571, 112-116 (2019).

26. Mosaliganti, K. R. et al. Size control of the inner ear via hydraulic feedback. eLife 8, e39596 (2019).

27. Imran Alsous, J. et al. Dynamics of hydraulic and contractile wave-mediated fluid transport during Drosophila oogenesis. Proc. Natl Acad. Sci. USA 118, e2019749118 (2021).

28. Timmons, L., Court, D. L. \& Fire, A. Ingestion of bacterially expressed dsRNAs can produce specific and potent genetic interference in Caenorhabditis elegans. Gene 263, 103-112 (2001).

29. Maddox, A. S., Habermann, B., Desai, A. \& Oegema, K. Distinct roles for two C. elegans anillins in the gonad and early embryo. Development 132, 2837-2848 (2005).

30. Green, R. A. et al. A high-resolution C. elegans essential gene network based on phenotypic profiling of a complex tissue. Cell 145, 470-482 (2011).
31. Andux, S. \& Ellis, R. E. Apoptosis maintains oocyte quality in aging Caenorhabditis elegans females. PLoS Genet. 4, e1000295 (2008).

32. Kim, S., Spike, C. \& Greenstein, D. in Germ Cell Development in C. elegans (ed. Schedl, T.) 277-320 (Springer, 2013).

33. Moris, N., Pina, C. \& Arias, A. M. Transition states and cell fate decisions in epigenetic landscapes. Nat. Rev. Genet. 17, 693-703 (2016).

34. Kimble, J. \& Page, D. C. The mysteries of sexual identity: the germ cell's perspective. Science 316, 400-401 (2007).

Publisher's note Springer Nature remains neutral with regard to jurisdictional claims in published maps and institutional affiliations.

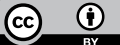

Open Access This article is licensed under a Creative Commons

Attribution 4.0 International License, which permits use, sharing, adaptation, distribution and reproduction in any medium or format, as long as you give appropriate credit to the original author(s) and the source, provide a link to the Creative Commons license, and indicate if changes were made. The images or other third party material in this article are included in the article's Creative Commons license, unless indicated otherwise in a credit line to the material. If material is not included in the article's Creative Commons license and your intended use is not permitted by statutory regulation or exceeds the permitted use, you will need to obtain permission directly from the copyright holder. To view a copy of this license, visit http://creativecommons. org/licenses/by/4.0/.

(c) The Author(s) 2021 


\section{Methods}

C. elegans strains. The following strains were used in this study:

\begin{tabular}{|c|c|}
\hline Strain name & Genotype \\
\hline OD95 & $\begin{array}{l}\text { unc-119(ed3) III; ItIs37 [Ppie-1::mCherry::his-58; unc-119(+)] IV; } \\
\text { ItIs38 [Ppie-1::gfp::PH(PLC1delta1); unc-119(+)] }\end{array}$ \\
\hline UM208 & $\begin{array}{l}\text { unc-119(ed3) III; ItIs81 [Ppie-1::gfp-TEV-Stag::ani-2; unc-119 (+)]; } \\
\text { ItIs44 [Ppie-1::mCherry::PH(PLC1delta1); unc-119(+)] IV }\end{array}$ \\
\hline SWG007 & $\begin{array}{l}\text { nmy-2(cp8 [nmy-2::GFP unc-119+]) l; ges/s001 [Pmex- } \\
\text { 5::LifeAct::mKate::nmy-2UTR, unc-119+] }\end{array}$ \\
\hline SWG016 & $\begin{array}{l}\text { ges/s001 [Pmex-5::LifeAct::mKate::nmy-2UTR, unc-119+]; unc- } \\
\text { 119(ed3) III; opls110 [lim-7p::YFP::actin + unc-119(+)] IV. }\end{array}$ \\
\hline SWG059 & $\begin{array}{l}\text { ges/s001 [Pmex-5::LifeAct::mKate::nmy-2UTR, unc-119+]; unc- } \\
\text { 119(ed3) ruls57 [pAZ147 pie-1p/GFP::C36E8.5] III }\end{array}$ \\
\hline SWG121 & $\begin{array}{l}\text { tonSi1 [mex-5p::Dendra2::his-66::tbb-2 3'-UTR]; nmy-2(cp8 [nmy- } \\
\text { 2::GFP unc-119+]) l; ges/s001 [Pmex-5::LifeAct::mKate2::nmy- } \\
\text { 2UTR, unc-119+] }\end{array}$ \\
\hline
\end{tabular}

Confocal imaging of living germlines. Young adult worms (24h post L4) were paralysed in $0.1 \%$ tetramisole (Sigma-Aldrich T1512) for $3 \mathrm{~min}$ on a cover slip precoated with $0.1 \%$ poly-L-lysine (Sigma-Aldrich P8920) and mounted on $2 \%$ agarose pads. Images were acquired with a spinning-disk confocal microscopy (Zeiss C-Apochromat, $\times 63 / 1.2 \mathrm{NA}$, Yokogawa CSU-X1 scan head and Hamamatsu ORCA-Flash4.0 camera).

Germ cell volume quantification. Confocal imaging was performed on UM208 young adult worms and 100 different $z$ planes spaced $0.5 \mu \mathrm{m}$ apart were acquired in 3 to 4 fields before being stitched together using Fiji's pairwise stitching plugin. The 3D segmentation on the membrane marker was performed using Imaris Cell plugin (version 9.2).

Rachis flow quantification. Confocal imaging was performed on SWG007 young adult worms and five different $z$ planes spaced $2 \mu \mathrm{m}$ apart were acquired every $10 \mathrm{~s}$. To capture full gonads, 3 to 4 fields were acquired and stitched together using Fiji's pairwise stitching plugin. The $z$ stack corresponding to the central-most plane of the rachis was kept for analysis. Flow velocities were obtained by PIV tracking of LifeAct::mKate timelapse acquisitions ${ }^{19}$. PIV template size was 16 pixels corresponding to $1.695 \mu \mathrm{m}$. The $x$ axis is defined as the distal to proximal axis. Due to geometric irregularities in the distal region of the rachis for ced-3(RNAi) germlines, we are only able to reliably identify steady velocity fields beyond $16 \%$ gonad length in the distal-proximal axis of these samples. The estimation of rachis flux $Q_{\mathrm{r}}$ from the velocity field is based on erosion-based segmentation to find the centreline and is described in Supplementary Information. Note that erosion-based segmentation fails near the proximal turn due to high curvatures. As a result, at the very proximal end and at $100 \%$ gonad length, the rachis flow into the turn is captured by the germ-cell-to-rachis current $J$ rather than $Q_{\mathrm{r}}$. In our analysis, this results in the rachis flux $Q_{\mathrm{r}}$ to drop to nearly zero at $100 \%$ gonad length (Fig. 1c), slightly before the rachis flux actually drops to zero at the last oocyte ${ }^{15}$.

Rachis opening perimeter. Confocal imaging was performed on UM208 young adult worms and 100 different $z$ planes spaced $0.5 \mu \mathrm{m}$ apart were acquired in 3 to 4 fields before stitching them together using Fijis pairwise stitching plugin. After maximal projections of the ANI-2::GFP slices corresponding to the upper half of the germline, a $2 \sigma$ Gaussian blur filter was applied and the perimeter of each opening was quantified semi-automatically using Fiji's wand tool. A conservative estimate for uncertainty is provided by the $z$ spacing, which is $0.5 \mu \mathrm{m}$ in this case.

RNAi experiments. RNAi experiments were performed by feeding ${ }^{28}$. L4 worms were grown at $20^{\circ} \mathrm{C}$ on feeding plates (NGM agar containing $1 \mathrm{mM}$ isopropyl- $\beta$-D-thiogalactoside and $50 \mu \mathrm{g} \mathrm{ml}^{-1}$ ampicillin) for $48 \mathrm{~h}$ before imaging, else specified otherwise.

FLUCS. Young adult worms were paralysed and mounted between a $3 \%$ agarose pad and a $18 \mathrm{~mm} \times 18 \mathrm{~mm}$ coverslip $(0.17 \mathrm{~mm}$ thickness). The sample was placed on a sapphire microscope slide equipped with Peltier cooling elements, sealed with dental silicone (Picodent twinsil, Picodent) and mounted on the FLUCS microscope stage ${ }^{6}$. The samples were imaged using $\times 60$ water immersion objective (UPLSAPO, 1.2NA, W-IR coating, Olympus), $\mathrm{D}_{2} \mathrm{O}$ (Sigma-Aldrich) as the immersion fluid, $488 \mathrm{~nm}$ and $561 \mathrm{~nm}$ laser illumination, $1 \times 1$ binning and $30 \mathrm{~s}$ intervals at $20 z$ planes $1 \mu \mathrm{m}$ apart (Olympus IX83, Yokogawa CSU-X1 scan head, Piezosystem Jena MIPOS 100, Andor iXon EMCCD DU-897 and Visitron VisiView software). Hydrodynamic flows were generated by scanning the $1,455 \mathrm{~nm}$ laser (Keopsys) at $1 \mathrm{kHz}$ through the rachis opening. Custom-written LabVIEW software superimposed the scan path of the infrared laser with the fluorescence image of the camera. Following an approximately 15 min FLUCS treatment, the $z$ stacks ( $1 \mu \mathrm{m}$ spacing) were acquired every $15 \mathrm{~min}$ for $3 \mathrm{~h}$. This allowed us to monitor the treated cell (FLUCS OUT, number of cells $n=19$; FLUCS CTRL, $n=21$ ) as well as its untreated neighbours (nearest, next-nearest and opposite; FLUCS OUT, $n=81$; FLUCS CTRL, $n=94$ ). Before and after FLUCS treatment, cell areas in each $z$ plane were measured with Fiji's freehand selection tool for integrating the volume of the treated cell (Supplementary Fig. 2f).

Mitotic and apoptotic rates in the germline. SWG59 (for mitosis) or SWG16 (for apoptosis) young adult worms were paralysed in $0.1 \%$ tetramisole (Sigma-Aldrich $\mathrm{T} 1512$ ) for $3 \mathrm{~min}$ on a cover slip precoated with $0.1 \%$ poly-L-lysine (Sigma-Aldrich P8920) and mounted on $2 \%$ agarose pads. Images were acquired with a spinning-disk confocal microscopy (Zeiss C-Apochromat, $\times 63 / 1.2 \mathrm{NA}$, Yokogawa CSU-X1 scan head and Hamamatsu ORCA-Flash4.0 camera) on 41 different $z$ planes spaced $1 \mu \mathrm{m}$ apart, recording one full stack every $30 \mathrm{~s}$. After maximal projections of individual movies in Fiji, the number of metaphase spindles or each new engulfment event-together with their position relative to the distal tip or proximal turn-were manually measured. The frequency of mitotic or apoptotic events along the total amount of imaging time was then binned to obtain a probability of event per unit length of the germline (Supplementary Fig. 1c). From these rates, an estimate of cumulative probability can be deduced. For example, at position $x$ of the gonad, considering that the rate of apoptosis per hour is $p_{\mathrm{a}}$, then the associated total probability of a cell to survive a period of $3 \mathrm{~h}$ is $p_{\mathrm{s}}=\left(1-p_{\mathrm{a}}\right)^{3}$ Hence, the estimated total cell death should be $\sim 100 \times\left(1-p_{s}\right) \%$.

Cell number density in the germline. UM208 young adult worms ( $24 \mathrm{~h}$ post L4) were paralysed in $0.1 \%$ tetramisole (Sigma-Aldrich T1512) for $3 \mathrm{~min}$ on a cover slip precoated with $0.1 \%$ poly-L-lysine (Sigma-Aldrich P8920) and mounted on $2 \%$ agarose pads. Images were acquired with spinning-disk confocal microscopy (Zeiss C-Apochromat, $\times 63 / 1.2 \mathrm{NA}$, Yokogawa CSU-X1 scan head and Hamamatsu ORCA-Flash4.0 camera) on 100 different $z$ planes spaced $0.5 \mu \mathrm{m}$ apart. To capture the full gonads, 3 to 4 fields were acquired and stitched together using Fijis pairwise stitching plugin. Curved gonads were straightened using a 300 pixels $(32 \mu \mathrm{m})$ wide line on the $x-y$ stacks using Fiji's straighten tool and resliced along the $z$ axis to get the cross-sections along the distal to proximal axis (semi-automatic using 'sideviews' Fiji macro). Cell numbers around the rachis were counted in 30 slices along the distal proximal axis and the average cell length along the distal proximal axis was estimated.

Estimating interface curvature. UM208 young adult worms ( $24 \mathrm{~h}$ post L4) were paralysed in $0.1 \%$ tetramisole (Sigma-Aldrich T1512) for $3 \mathrm{~min}$ on a cover slip precoated with $0.1 \%$ poly-L-lysine (Sigma-Aldrich P8920) and mounted on $2 \%$ agarose pads. Images were acquired with spinning-disk confocal microscopy (Zeiss C-Apochromat, $\times 63 / 1.2 \mathrm{NA}$, Yokogawa CSU-X1 scan head and Hamamatsu ORCA-Flash4.0 camera) on 100 different $z$ planes spaced $0.5 \mu \mathrm{m}$ apart. To capture the full gonads, 3 to 4 fields were acquired and stitched together using Fijis pairwise stitching plugin. Curved gonads were straightened using a 300 pixels $(32 \mu \mathrm{m})$ wide line on the $x-y$ stacks using Fijis straighten tool and resliced along the $z$ axis to get the cross-sections along the distal to proximal axis (semi-automatic using 'sideviews' Fiji macro). For 1/100th of the cross-section slices, the curvature along all the cell-cell interfaces were calculated by fitting a 5 point B-spline curve using the Kappa plugin in Fiji. The average curvature $\left(\mu \mathrm{m}^{-1}\right)$ at each cross-section was then plotted along the distal to proximal axis. A smooth curved surface of a cell of $10.0 \mu \mathrm{m}$ height and $0.5 \mu \mathrm{m}$ maximal deflection would correspond to a curvature of $\sim 0.04 \mu \mathrm{m}^{-1}$, larger than the estimated curvatures shown in Supplementary Fig. $4 \mathrm{~b}$.

Reporting Summary. Further information on research design is available in the Nature Research Reporting Summary linked to this article.

\section{Data availability}

All data generated or analysed in this study are available from the corresponding authors upon reasonable request.

\section{Code availability}

Codes to analyse the data and perform numeric calculations are available from the corresponding authors upon reasonable request.

\section{Acknowledgements}

S.W.G. was supported by the DFG (SPP 1782, GSC 97, GR 3271/2, GR 3271/3 and GR 3271/4) and the European Research Council (grant no. 742712). A.M. acknowledges support from the Joachim Herz Stiftung. J.P. acknowledges support from EMBO (ALTF 975-2019). B.T.L. acknowledges support through a National Science Foundation Graduate Research Fellowship. A.W.F. acknowledges support from the MaxSynBio consortium. M.K. acknowledges support from the European Research Council (grant no. 853619, GHOSTS). We thank the staff and students of the 2016 and 2017 MBL Physiology courses where this work was started, particularly J. Brzostowski, E. Eck, N. King, J. Lippincott-Schwartz, M. Morrison, C. Ott, B. Pennycook, R. Phillips and N. Ratneyeke. We thank M. Mittasch for help with FLUCS; the light microscopy facilities of BIOTEC and MPI-CBG for support; and T. Middlekoop, L. Hubatsch and K. Ishihara for discussions and comments on the manuscript. 


\section{Author contributions}

N.T.C., A.M., J.P., F.J. and S.W.G. designed the research, analysed the data and wrote the manuscript. N.T.C. and J.P. performed the experiments with support from B.T.L. and R.A. J.P. performed FLUCS with support from A.W.F. and M.K. A.M., S.W.G. and F.J. developed the theory with support from S.F. N.T.C., A.M. and J.P. contributed equally and are listed in alphabetical order.

\section{Competing interests}

The authors declare no competing interests.

\section{Additional information}

Extended data is available for this paper at https://doi.org/10.1038/s41567-021-01235-x. Supplementary information The online version contains supplementary material available at https://doi.org/10.1038/s41567-021-01235-x.

Correspondence and requests for materials should be addressed to F.J. or S.W.G. Peer review information Nature Physics thanks Marino Arroyo and the other, anonymous, reviewer(s) for their contribution to the peer review of this work.

Reprints and permissions information is available at www.nature.com/reprints. 
A

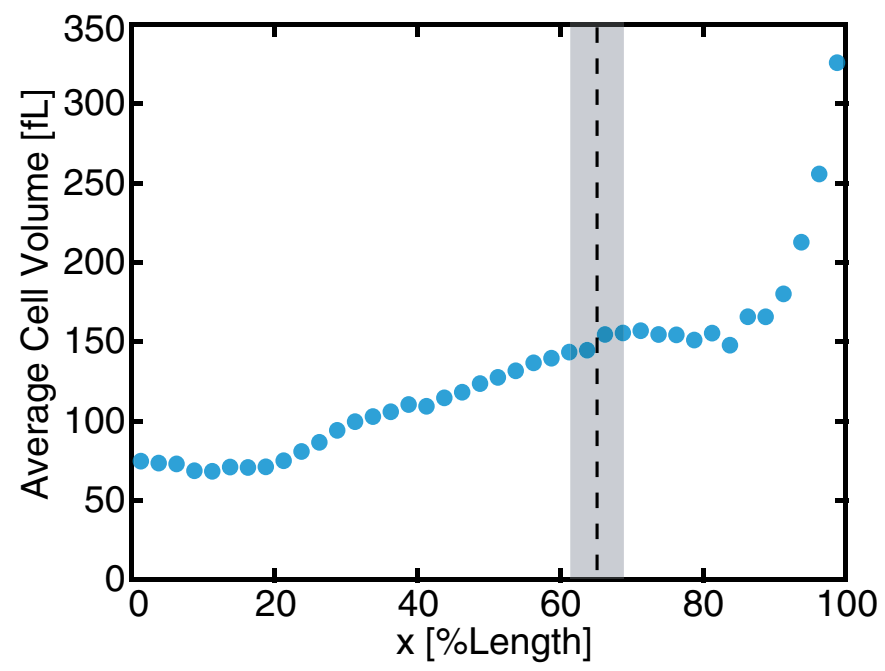

C

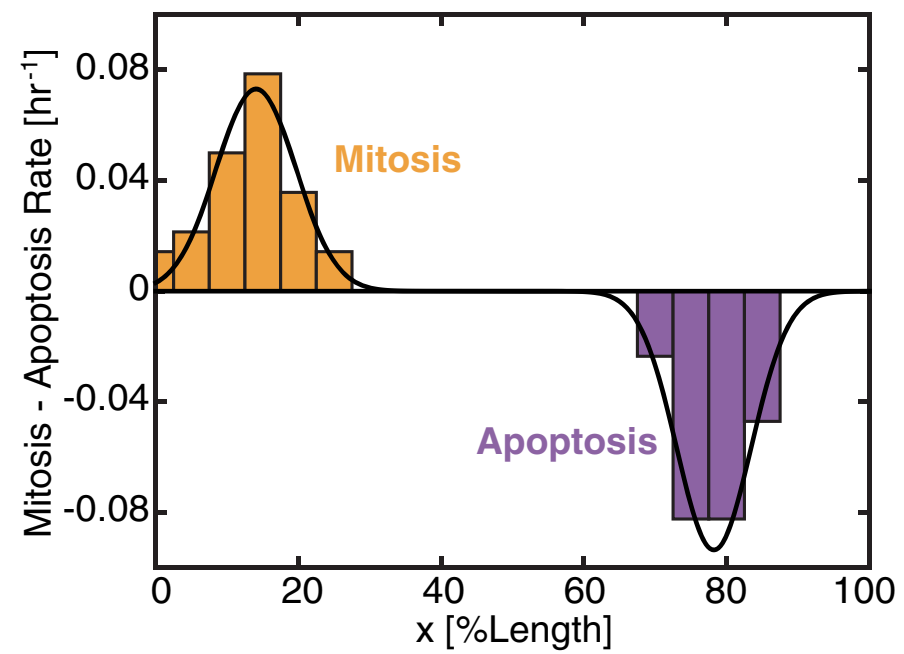

E

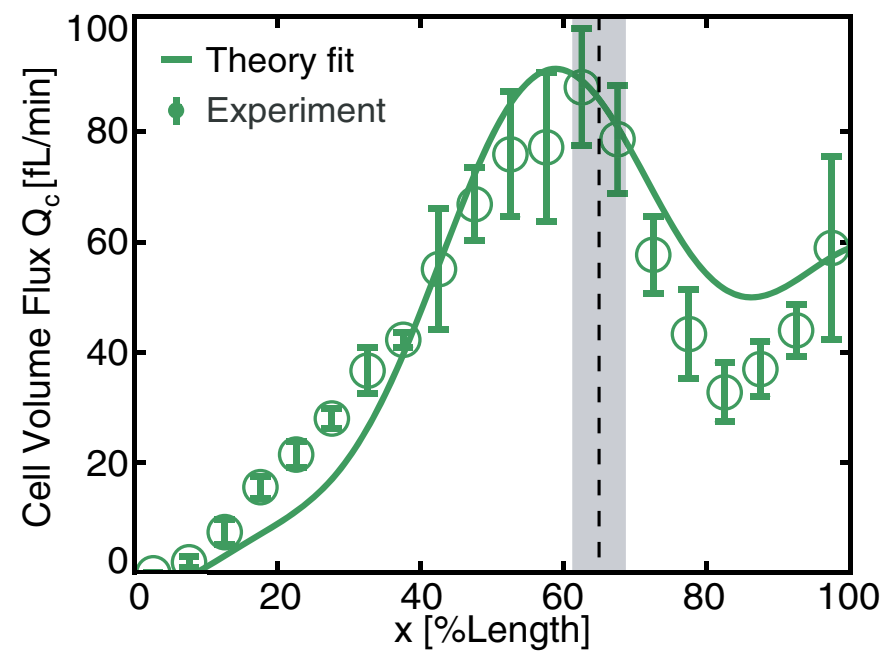

B

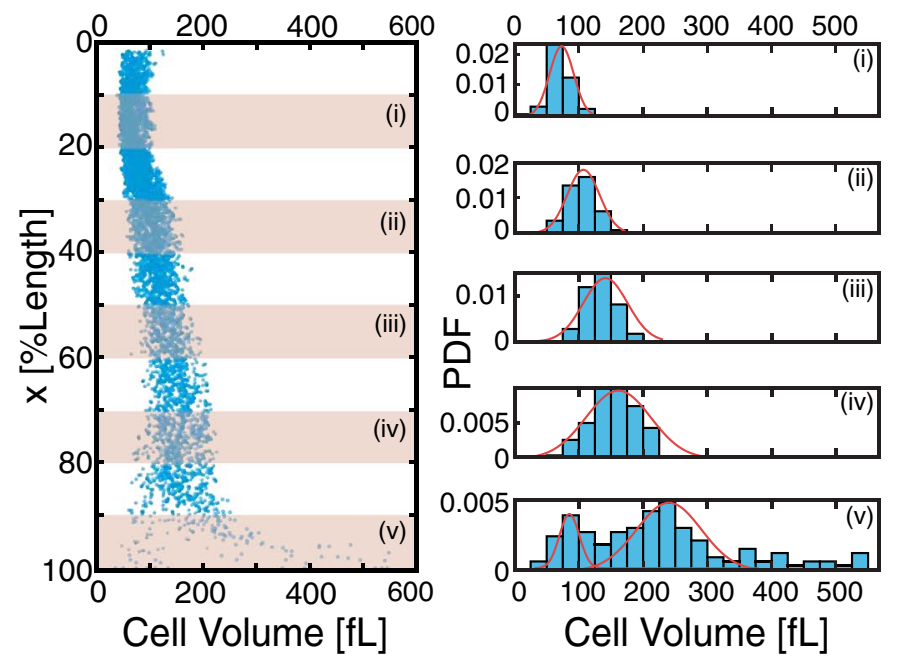

D

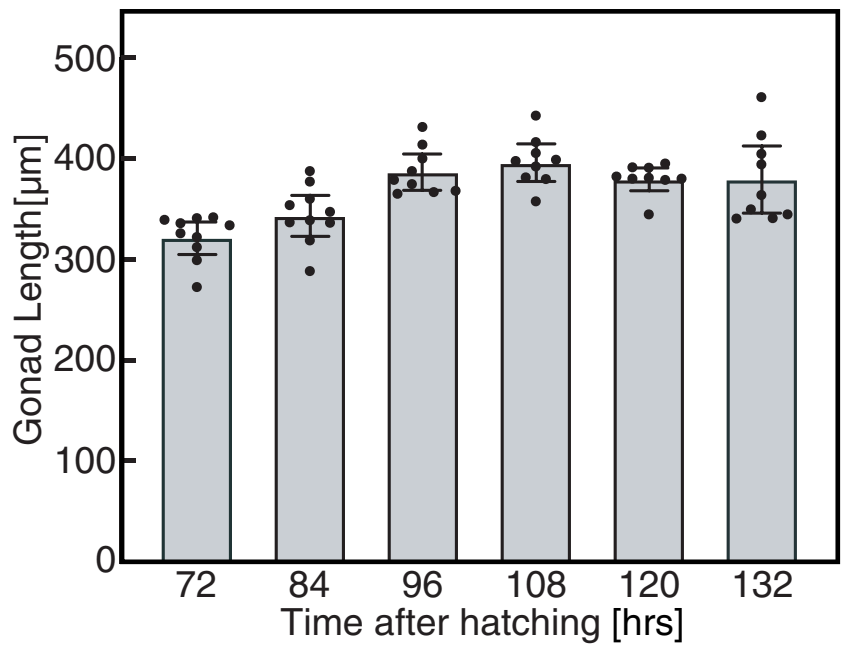

F

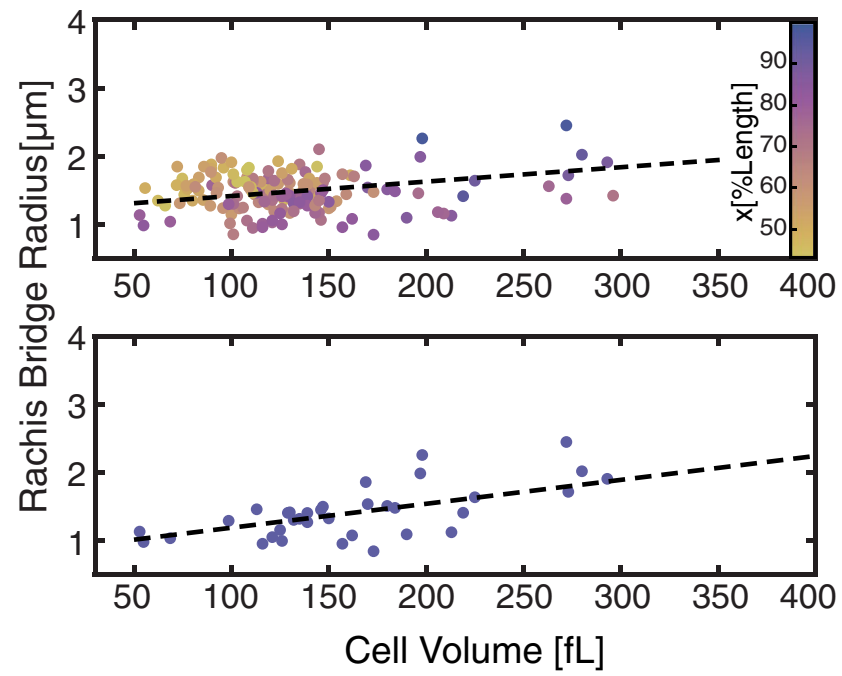

Extended Data Fig. 1 | See next page for caption. 


\section{NATURE PHYSICS}

Extended Data Fig. 1 | Volumes and fluxes in nematode germline. A, Average volume of germ cells along the distal to proximal axis (18 germlines, bin size $2.5 \%$ gonad length). Vertical dashed line and grey region indicate the transition region between growth modes (Fig. 1b). B, Transition from a unimodal to a bimodal distribution of germ cell volumes (left: blue dots, individual germ cell volumes as in Fig. 1b). Histograms of germ cell volumes in five different regions along the gonad (right). The distribution of germ cell volumes is unimodal (Gaussian fits in (i)-(iv)) in the distal region and bimodal in the proximal region (superposition of two Gaussian's in (v)). C, Rates of mitotic (positive) and apoptotic events (negative) along germline length, analysed from 6 gonads for 30 mitotic events (Supplementary Video 2), and 4 gonads for 20 apoptotic events (Supplementary Video 3, see supplementary text). D, Gonad length as a function of time post hatching determined in at least nine worms. The adult germline length remains approximately constant. $\mathbf{E}$, Green open circles, cell volume flux $Q_{c}$ along the gonad. This flux peaks around $60 \%$ gonad length and decreases to a finite value, indicating outflow of cells at the proximal turn. Grey regions indicate the transition between growth modes (Fig. 1b). Green line, theory fit (see supplementary text). F, Correlation of rachis bridge radii with cell volumes. Top, rachis bridge radius plotted against cell volumes for individual germ cells along the gonad (color denotes position $x$ ). Rachis bridge radii correlate with germ cell volumes with a Pearson coefficient of 0.43 . Bottom, restricting the analysis to the proximal regime with a broader distribution of germ cell volumes (beyond $75 \%$ gonad length) reveals a larger degree of correlation with a Person coefficient of 0.75 . Errorbars indicate the error of the mean at $95 \%$ confidence. 

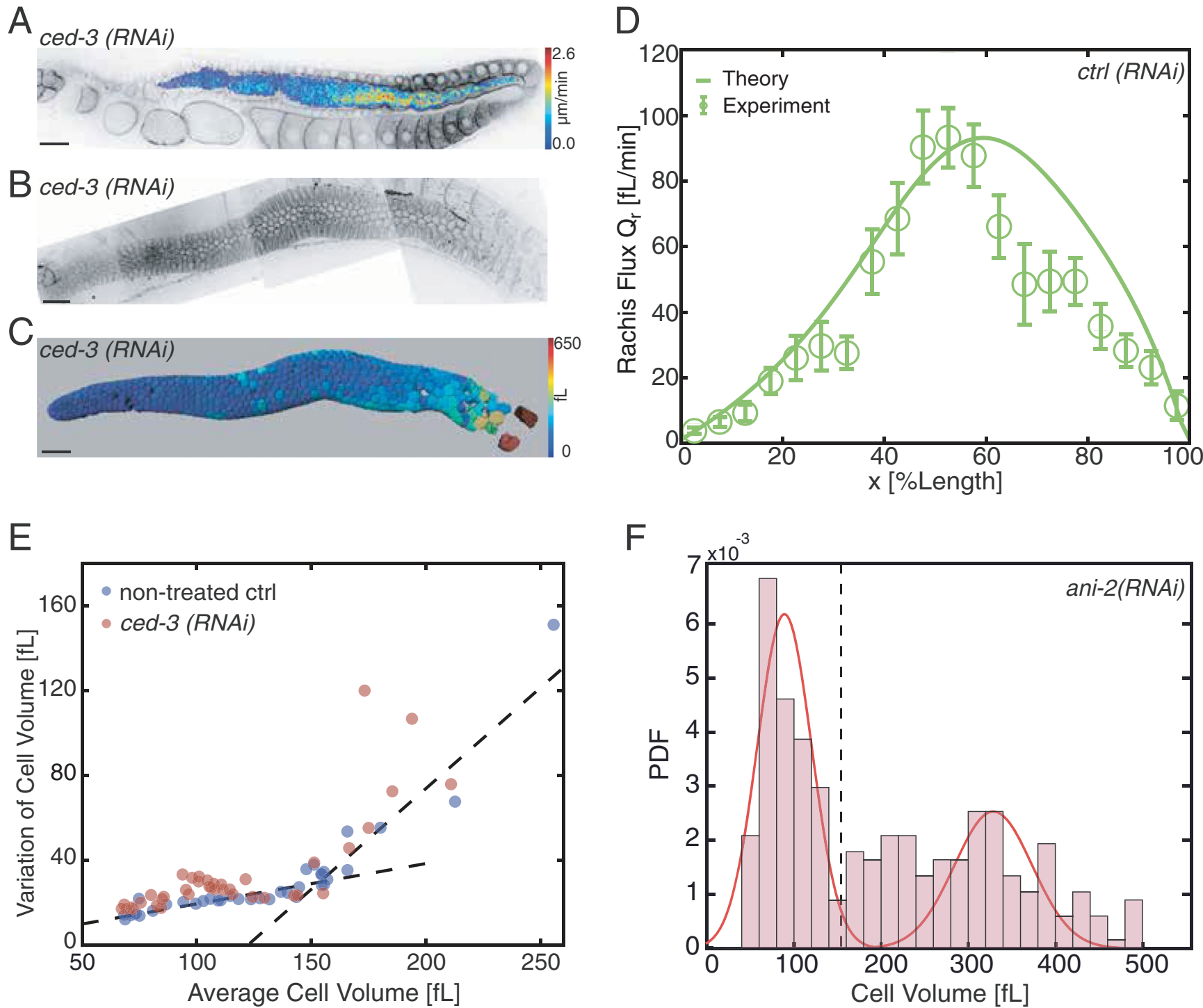

$\mathrm{F}$
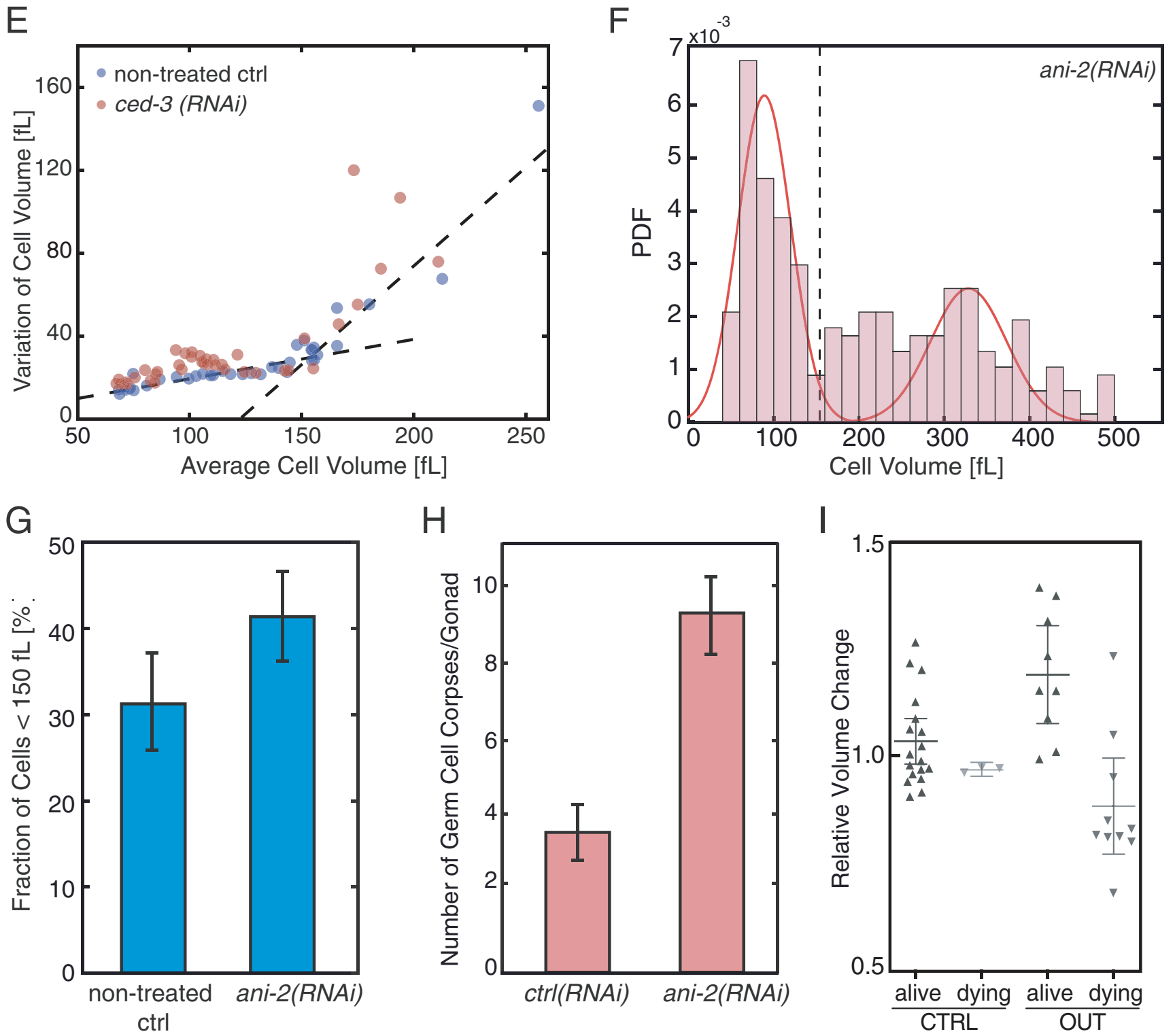

Extended Data Fig. 2 | See next page for caption. 


\section{NATURE PHYSICS}

Extended Data Fig. 2 | Genetic and physical perturbations of germ cells. A-C, Representative ced-3(RNAi) gonads. A, PIV on-axis speed (color-code) overlaid on a central cross section of a gonad expressing LifeAct::mKate treated with ced-3(RNAi). B, Maximum intensity projection of an adult gonad treated with ced-3(RNAi), where the cell membrane expressing marker mCherry:: $\mathrm{PH}$-domain was imaged. $\mathrm{C}, 3 \mathrm{D}$ rendering of a representative ced-3(RNAi) germline where germ cells were segmented. Color code indicates germ cell volume. D, Open circles, rachis flux $Q_{r}$ for the $L 4440$ control RNAi from 10 gonad arms. Solid line, theory fit (see Supplementary Information). E, Standard deviation of cell volumes plotted against average cell volume for non-RNAi and ced-3(RNAi) germlines. F, Distribution of germ cell volumes located between $85 \%-100 \%$ gonad length treated with ani-2(RNAi) for 24 hours; solid curves indicate superposition of two Gaussian distributions; vertical dash line indicates crossover volume of $150 \mathrm{fL}$. G, Fraction of germ cells smaller than $150 \mathrm{fL}$ located at proximal end ( $85 \%-100 \%$ gonad length) for non-treated control and ani-2(RNAi) condition. $\mathrm{H}$, Number of germ cell corpses per gonad arm under $L 4440$ control(RNAi) ( $n=2)$ and ani-2(RNAi) treatment $(n=3)$, identified by characteristic apoptotic rounding (see Supplementary Fig. 3). I, Relative volume change of germ cells during the approximately $15 \mathrm{~min}$ of thermoviscous pumping, for the FLUCS CTRL and FLUCS OUT experiment (Fig. 3c). Scale bars, $20 \mu \mathrm{m}$. Error bars represent error of the mean at $95 \%$ confidence. 
A
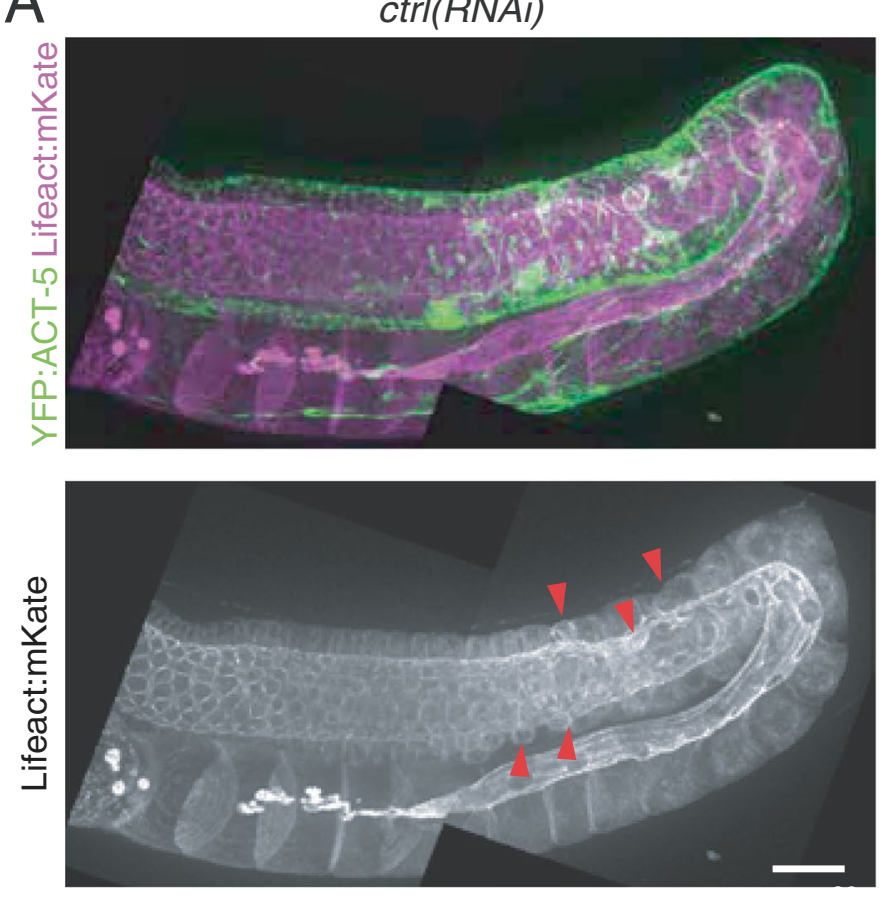

ani-2(RNAi)
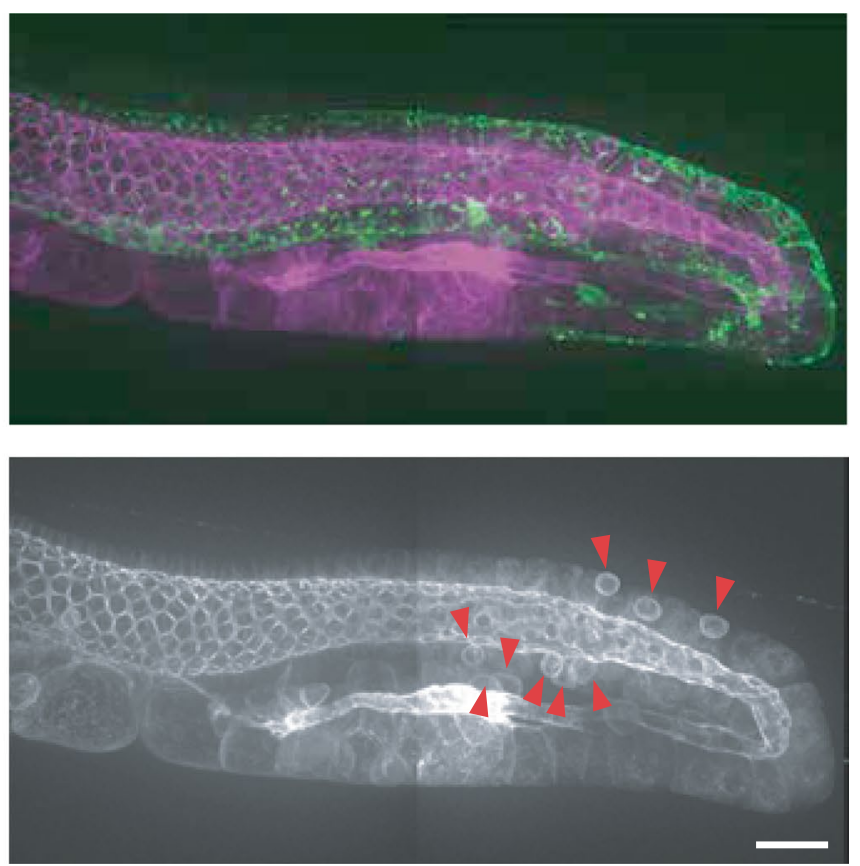

Extended Data Fig. 3 | Apoptotic rounding of germ cells in non-treated and ani-2(RNAi) treated germlines. A, Maximum intensity projections of representative adult gonad (SWG016) treated with $L 4440$ control(RNAi) (left panels) or ani-2(RNAi) (right panels) for 24 hours, showing actin in the germ cells (magenta) and in the surrounding sheath cells (green) engulfing the dying germ cells. Lower panels show actin in germ cells. Red arrows indicate germ cells with characteristic features of apoptotic rounding. Scale bars, $20 \mu \mathrm{m}$. 
A

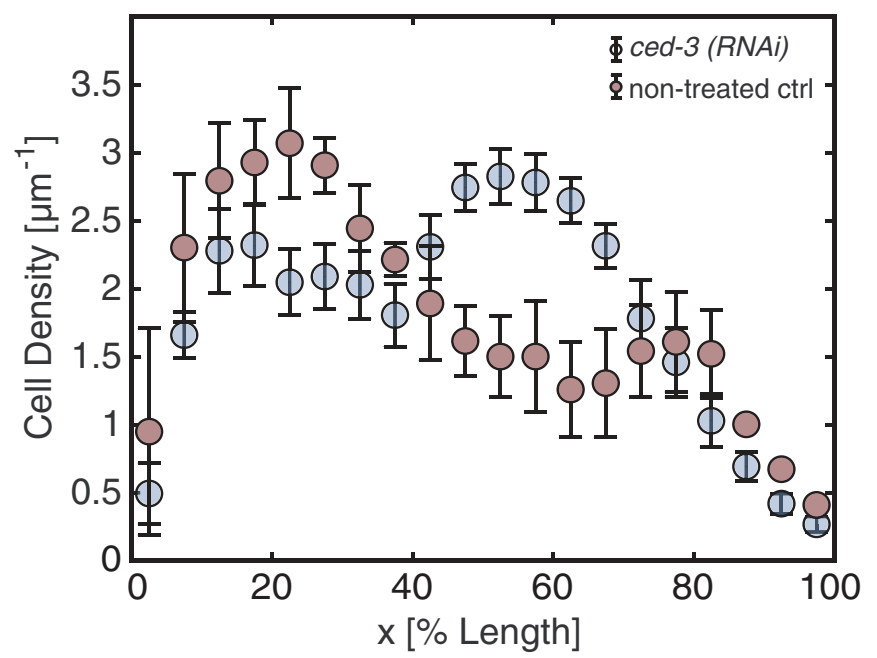

B

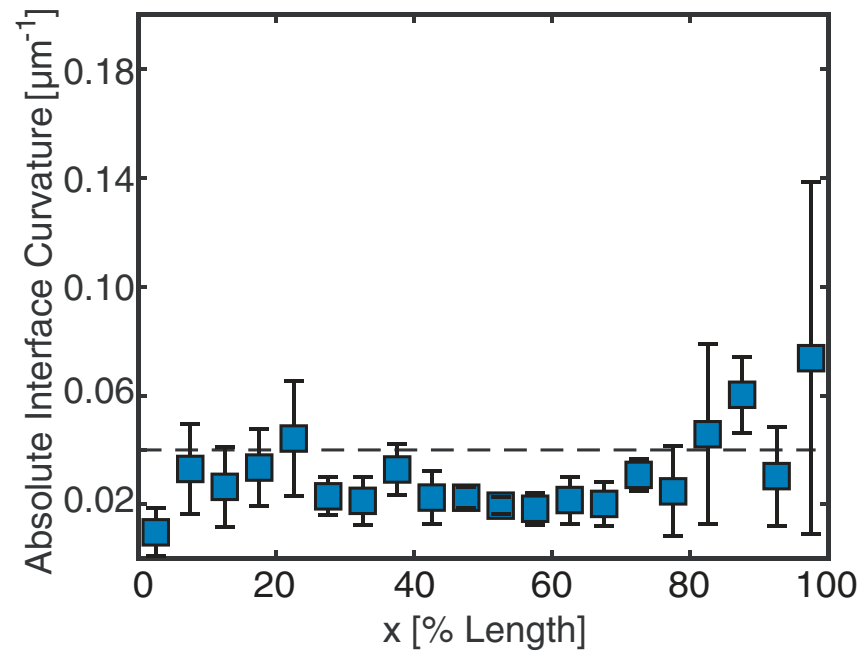

Extended Data Fig. 4 | Cell density and interface curvature along the germline. A, Linear germ cell density profiles are shown for non-treated ( $n=11$ ) and ced-3(RNAi) treated ( $n=5)$ adult gonads. B, Spatial profile of mean absolute curvatures are shown (242 interfaces). Dashed line indicates curvature corresponding to a $0.5 \mu \mathrm{m}$ central deflection of a $10 \mu \mathrm{m}$ interface, below which we define the curvatures to be negligible (see Methods). Error bars represent error of the mean at $95 \%$ confidence. 


\section{Reporting Summary}

Nature Research wishes to improve the reproducibility of the work that we publish. This form provides structure for consistency and transparency in reporting. For further information on Nature Research policies, see our Editorial Policies and the Editorial Policy Checklist.

\section{Statistics}

For all statistical analyses, confirm that the following items are present in the figure legend, table legend, main text, or Methods section.

n/a Confirmed

$\square \bigotimes$ The exact sample size $(n)$ for each experimental group/condition, given as a discrete number and unit of measurement

Х $\square$ A statement on whether measurements were taken from distinct samples or whether the same sample was measured repeatedly

The statistical test(s) used AND whether they are one- or two-sided

$\square$ Only common tests should be described solely by name; describe more complex techniques in the Methods section.

Х $\square$ A description of all covariates tested

Х $\square$ A description of any assumptions or corrections, such as tests of normality and adjustment for multiple comparisons

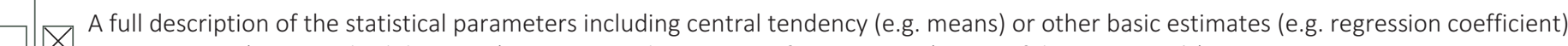

$\bigotimes$ AND variation (e.g. standard deviation) or associated estimates of uncertainty (e.g. confidence intervals)

X $\square$ For null hypothesis testing, the test statistic (e.g. $F, t, r$ ) with confidence intervals, effect sizes, degrees of freedom and $P$ value noted

Give $P$ values as exact values whenever suitable.

Х $\square$ For Bayesian analysis, information on the choice of priors and Markov chain Monte Carlo settings

Х $\square$ For hierarchical and complex designs, identification of the appropriate level for tests and full reporting of outcomes

Х $\square$ Estimates of effect sizes (e.g. Cohen's $d$, Pearson's $r$ ), indicating how they were calculated

Our web collection on statistics for biologists contains articles on many of the points above.

\section{Software and code}

Policy information about availability of computer code

Data collection Fiji,Scientific Python, Matlab, LabView

Data analysis Scientific Python, Matlab, IMARIS Software

For manuscripts utilizing custom algorithms or software that are central to the research but not yet described in published literature, software must be made available to editors and reviewers. We strongly encourage code deposition in a community repository (e.g. GitHub). See the Nature Research guidelines for submitting code \& software for further information.

\section{Data}

Policy information about availability of data

All manuscripts must include a data availability statement. This statement should provide the following information, where applicable:

- Accession codes, unique identifiers, or web links for publicly available datasets

- A list of figures that have associated raw data

- A description of any restrictions on data availability 


\section{Field-specific reporting}

Please select the one below that is the best fit for your research. If you are not sure, read the appropriate sections before making your selection. \Life sciences

\section{Life sciences study design}

All studies must disclose on these points even when the disclosure is negative.

Sample size We analyzed gonad arms in individual C.elegans hermaphrodite worms, between 5 to 20 individual worms per experiment as stated in the figure captions.

Data exclusions The results of Imaris segmentation for germ cells volumes dot plots (figures 1 and 4), were filtered with a bandwidth of 3 standard deviation around the mean.

Replication We combined fields measured from different C. elegans hermaphrodite worms, which were similar to each other, hence replicability is ensured

Randomization Not applicable as we pursued quantitiative fits of fields between theory and experiment

Blinding

Not applicable as we pursued quantitiative fits of fields between theory and experiment

\section{Reporting for specific materials, systems and methods}

We require information from authors about some types of materials, experimental systems and methods used in many studies. Here, indicate whether each material, system or method listed is relevant to your study. If you are not sure if a list item applies to your research, read the appropriate section before selecting a response.

Materials \& experimental systems

$\mathrm{n} / \mathrm{a}$ Involved in the study

\ $\square$ Antibodies

\ $\square$ Eukaryotic cell lines

Х $\square$ Palaeontology and archaeology

$\square \bigotimes$ Animals and other organisms

$\bigotimes \square$ Human research participants

$\bigotimes \square$ Clinical data

$\bigotimes \square$ Dual use research of concern

\section{Animals and other organisms}

Policy information about studies involving animals; ARRIVE guidelines recommended for reporting animal research

Laboratory animals

Wild animals

Field-collected samples

Ethics oversight

\begin{tabular}{l|l}
\multicolumn{2}{l}{ Methods } \\
\hline n/a & Involved in the study \\
$\square$ & $\square$ ChIP-seq \\
$\square$ & $\square$ Flow cytometry \\
$\square$ & $\square$ MRI-based neuroimaging
\end{tabular}

\) $\square$ MRI-based neuroimaging

Note that full information on the approval of the study protocol must also be provided in the manuscript. 